
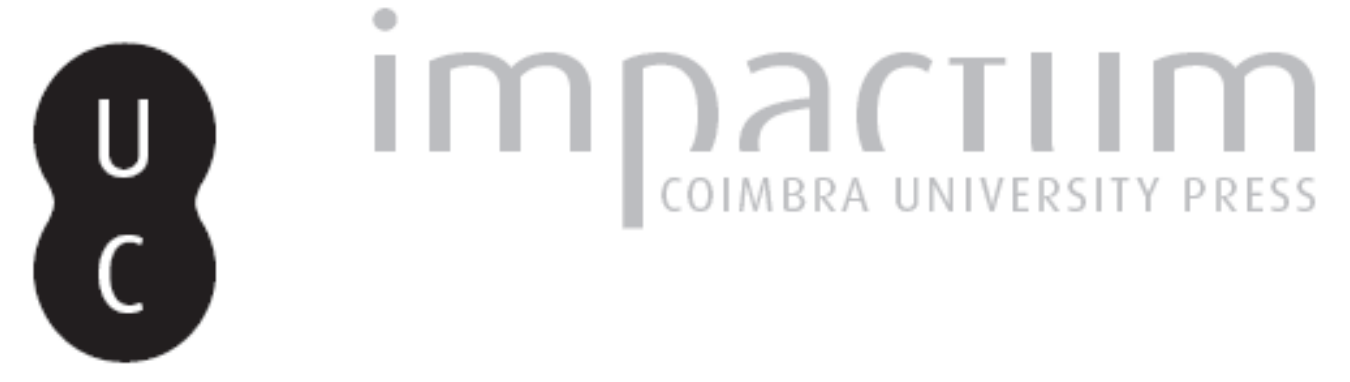

\title{
Plataforma integrada de gestão e accionamento de cenários
}

\begin{tabular}{|c|c|}
\hline Autor(es): & $\begin{array}{l}\text { Neri, Luís Manuel Guerra; Neves, Maria João Cancela de Amorim Seiça; } \\
\text { Antunes, Luís Correia; Paixão, Cláudia Isabel da Silva }\end{array}$ \\
\hline Publicado por: & Associação Portuguesa de Riscos, Prevenção e Segurança \\
\hline $\begin{array}{l}\text { URL } \\
\text { persistente: }\end{array}$ & URI:http://hdl.handle.net/10316.2/36083 \\
\hline DOl: & DOI:http://dx.doi.org/10.14195/1647-7723_18_27 \\
\hline Accessed : & 26-Apr-2023 09:47:27 \\
\hline
\end{tabular}

A navegação consulta e descarregamento dos títulos inseridos nas Bibliotecas Digitais UC Digitalis, UC Pombalina e UC Impactum, pressupõem a aceitação plena e sem reservas dos Termos e Condições de Uso destas Bibliotecas Digitais, disponíveis em https://digitalis.uc.pt/pt-pt/termos.

Conforme exposto nos referidos Termos e Condições de Uso, o descarregamento de títulos de acesso restrito requer uma licença válida de autorização devendo o utilizador aceder ao(s) documento(s) a partir de um endereço de IP da instituição detentora da supramencionada licença.

Ao utilizador é apenas permitido o descarregamento para uso pessoal, pelo que o emprego do(s) título(s) descarregado(s) para outro fim, designadamente comercial, carece de autorização do respetivo autor ou editor da obra.

Na medida em que todas as obras da UC Digitalis se encontram protegidas pelo Código do Direito de Autor e Direitos Conexos e demais legislação aplicável, toda a cópia, parcial ou total, deste documento, nos casos em que é legalmente admitida, deverá conter ou fazer-se acompanhar por este aviso.

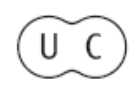




\section{territorium}

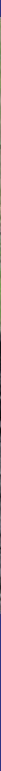

\section{Afirmar as Ciências Cindínicas}

Revista da Associação Portuguesa de Riscos, Prevenção e Segurança 


\section{NOTAS, NOTÍCIAS E RECENSÕES}

PLATAFORMA INTEGRADA DE GESTÃO E ACCIONAMENTO DE CENÁRIOS*

Luís Manuel Guerra Neri

Presidente do Serviço Regional de Protecção Civil, IP-RAM luis.neri@procivmadeira.pt

Maria João Cancela de Amorim Seiça Neves

Directora da Direcção Regional de Informação Geográfica e Ordenamento do Território mjoaoneves.sra@gov-madeira.pt

Luís Correia Antunes

Direcção Regional de Informação Geográfica e Ordenamento do Território luisantunes.sra@gov-madeira.pt

Cláudia Isabel da Silva Paixão Serviço Regional de Protecção Civil, IP-RAM claudia.paixao@procivmadeira.pt

\section{Introdução}

A Região Autónoma da Madeira apresenta um conjunto de riscos específicos, inerentes ao conjunto das ilhas que a constituem e, no que se refere à sua itha principal Itha da Madeira -, a orografia apresenta-se favorável a movimentação de massas e cheias rápidas. Para além disso, a existência de uma área florestal de grande importância regional e que constitui Património da Humanidade - a Laurissilva - coloca o risco de incêndio florestal como um dos riscos com maior probabilidade e, naturalmente, que congrega maior preocupação no território.

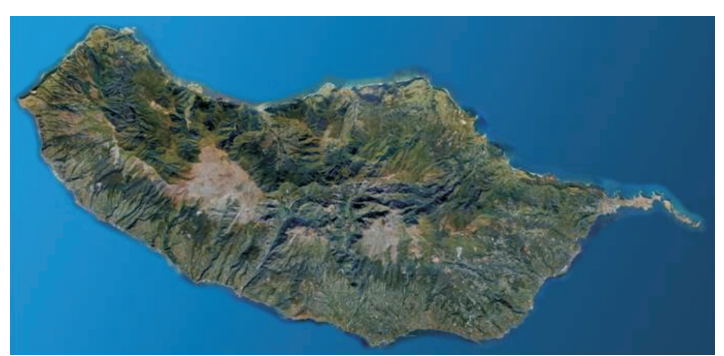

Fig. 1 - Ilha da Madeira - Cobertura aerofotográfica de 2007. Fonte: DRIGOT, 2007.

A detecção prematura dos riscos naturais permite um accionamento rápido de planos de emergência e respectivos meios, sendo este propósito essencial para a salvaguarda, na sua maior amplitude possível, de vidas humanas e bens. A implementação de mecanismos de alerta de ocorrências de apoio à intervenção rápida dos meios de emergência e socorro, envolve uma plataforma tecnológica com forte predominância das TIC - Tecnologias de Informação e Comunicação -, que permita o acesso a dados disponibilizados por vários sistemas de detecção. Desta maneira, será possível processar informação proveniente de sensores distribuídos em locais estratégicos da ilha, indicadores do desenvolvimento de um determinado risco natural. A posterior utilização dos Sistemas de Informação Geográfica permite facilitar a localização, interpretação, cruzamento de dados, planeamento, modelação e gestão de meios, que se pretendem para a resolução da ocorrência.

Com a activação de alertas de ocorrências serão desencadeados certos processos e procedimentos:

- Modelação da ocorrência: permite a previsão do desenvolvimento da ocorrência e antever cenários;

- Activação de planos de intervenção: são activados os planos prévios de intervenção permitindo uma actuação rápida, comunicação directa com as viaturas envolvidas, transmissão de coordenadas e localização das ocorrências para os sistemas de navegação nelas acoplados;

* O texto deste artigo corresponde à comunicação apresentada ao II Congresso Internacional de Riscos e VI Encontro Nacional, tendo sido submetido para revisão em 07-06-2010, tendo sido aceite para publicação em 21-08-2010. Este artigo é parte integrante da Revista Territorium, n. ${ }^{\circ} 18,2011$, ${ }^{\circledR}$ RIscos, ISBN: 0872- 8941. 
- Monitorização de cenários: o acesso ao cenário da ocorrência numa única plataforma permite-nos visualizar as viaturas de intervenção e restantes recursos (através da sua localização por GPS) sobre vários mapas de base e temáticos, proporcionando um precioso auxilio à tomada de decisões rápidas e uma eficaz gestão dos recursos no terreno.

O presente projecto será elaborado em parceria entre a Direcção Regional de Informação Geográfica e Ordenamento do Território - DRIGOT - e o Serviço Regional de Protecção Civil IP-RAM - SRPC - e tem como objectivo a implementação de um sistema de apoio à decisão operacional, de suporte à gestão de alertas e incidentes do SRPC IP-RAM. Este sistema inclui o Subsistema de Gestão Operações de Socorro e módulos de suporte.

\section{Módulos da aplicação}

A plataforma pretende cobrir, numa primeira fase, três tipos de riscos naturais: (1) Movimentação de massas; (2) Fogos Florestais; (3) Cheias rápidas. Em cada um destes módulos serão criadas ferramentas próprias adaptadas a cada tipo de riscos. Em todos eles, a estratégia de opções será idêntica:

a) Definição de cenários;

b) Detecção e monitorização dos riscos;

c) Modelação dos cenários das ocorrências;

d) Actualização permanente de cartografia de riscos;

e) Plano Prévio de Intervenção com definição da localização e números de recursos;

f) Localização e accionamento de sistemas de alerta;

g) Accionamento e despacho de recursos;

\section{Módulo 1 - Risco de movimentação de massas}

O objectivo deste processo será a integração, numa só plataforma, de meios para detectar, modelar, monitorizar e alertar fenómenos de movimentação de massas. A integração numa só plataforma permite-nos cruzar dados de várias épocas e de vários métodos de medição de grandeza, atingindo, de uma forma mais adequada, os resultados pretendidos.

Assim, para os processos de detecção de zonas de risco de movimentação de massas e alerta de deslizamento, os trabalhos foram divididos em diversas fases:

A. Detecção: Captura de uma série temporal de imagens de satélite com sensores In-SAR - Interferometric Synthetic Aperture Radar -, através dos satélites ERS1, ERS2, JERS, IRS E Radarsat. As imagens, capturadas mensalmente, num espaço de temporal de 3 a 4 anos, vão auxiliar na detecção de zonas de movimentação de massas desconhecidas na llha da Madeira. Após a detecção destas áreas, efectuar-se-á uma análise local para verificar a existência desse fenómeno e, caso se confirme, quantificar com precisão os vectores velocidade, modelação (posterior previsão) e a sua monitorização.

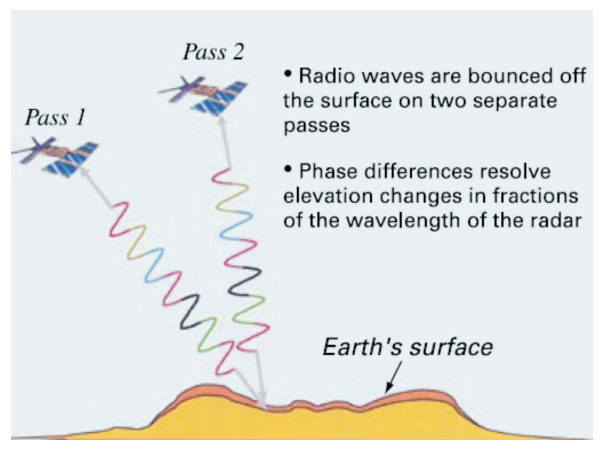

Fig. 2 - Captação de imagens In-SAR. Fonte: U.S. Geological Suevey, 2005.

B. Monitorização: Esta fase será executada em zonas de deslizamento de massas conhecidas ou em fase de estudo, permitindo uma avaliação mais precisa e rigorosa da área de risco. A monitorização em 4 Dimensões terá uma frequência consoante o grau de susceptibilidade e da grandeza do vector velocidade. Consoante a área - acessos e o grau de perigosidade - serão utilizadas as tecnologias Laser Aéreo, vulgo LIDAR - Light Detection and Ranging - ou o Laser and Scanning terrestre. Esta fase será fundamental para a definição precisa da área e para a tomada de decisão (consolidação de arribas de terrenos) e/ou colocação de um sistema de alerta para a rápida intervenção dos meios de socorro e emergência.

C. Modelação: Com o tratamento de dados das várias técnicas (Imagens InSAR, LIDAR, Laser Scanning e sistema robótico de alerta) obtém-se cartografia precisa das áreas a intervir e uma modelação do tipo de movimentação de massas, combinando o DEM Digital Elevation Model - com precisão centimétrica, os vectores velocidades e os dados históricos, entre outros dados relevantes. Esta informação será fundamental na prevenção de riscos para a vida humana, planeamento e acções de intervenção em caso de desastre natural (deslizamento de terras, desabamento de arribas, etc) servindo ainda como ferramenta para o Ordenamento do Território, com possível aplicação nos PEMPC - Planos de Emergência Municipais de Protecção Civil. Esta cartografia, associada a cartas de modelações e previsões, serão constantemente actualizadas sempre que existirem novas informações. 


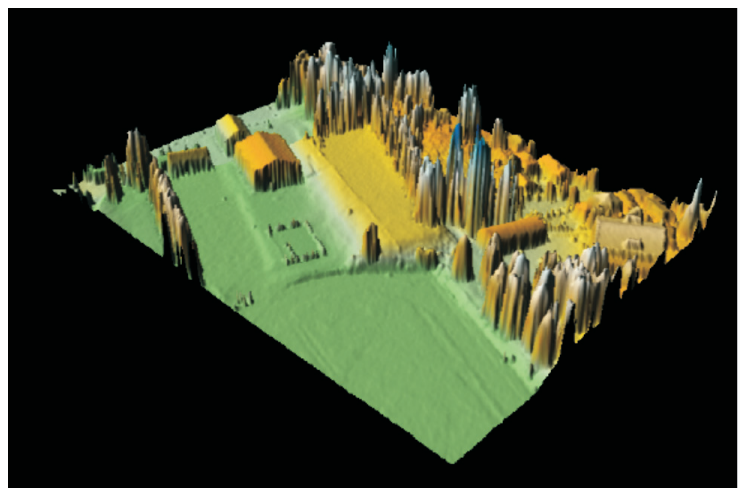

Fig. 3 - MDS - Modelo Digital de Superfície - Modelo que descreve a superfície do terreno, incluindo estruturas.

Fonte: Anais XIII Simpósio Brasileiro de Sensoriamento Remoto, 2007

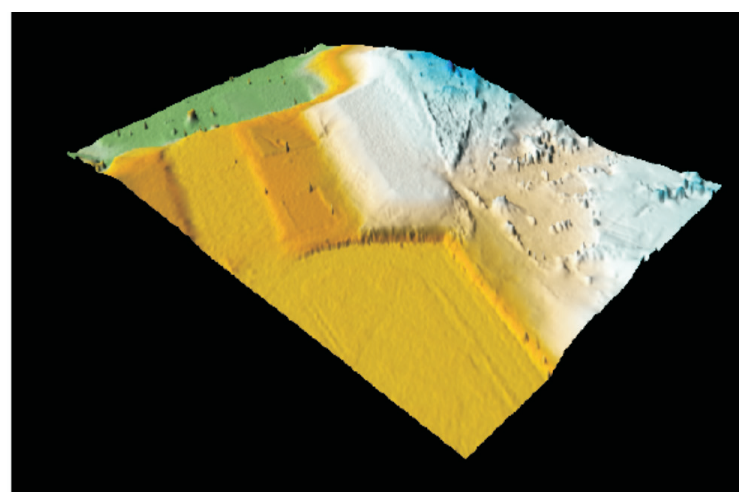

Fig. 4 - MDT - Modelo Digital do Terreno - Modelo que descreve a altimetria.

Fonte: Anais XIII Simpósio Brasileiro de Sensoriamento Remoto, 2007

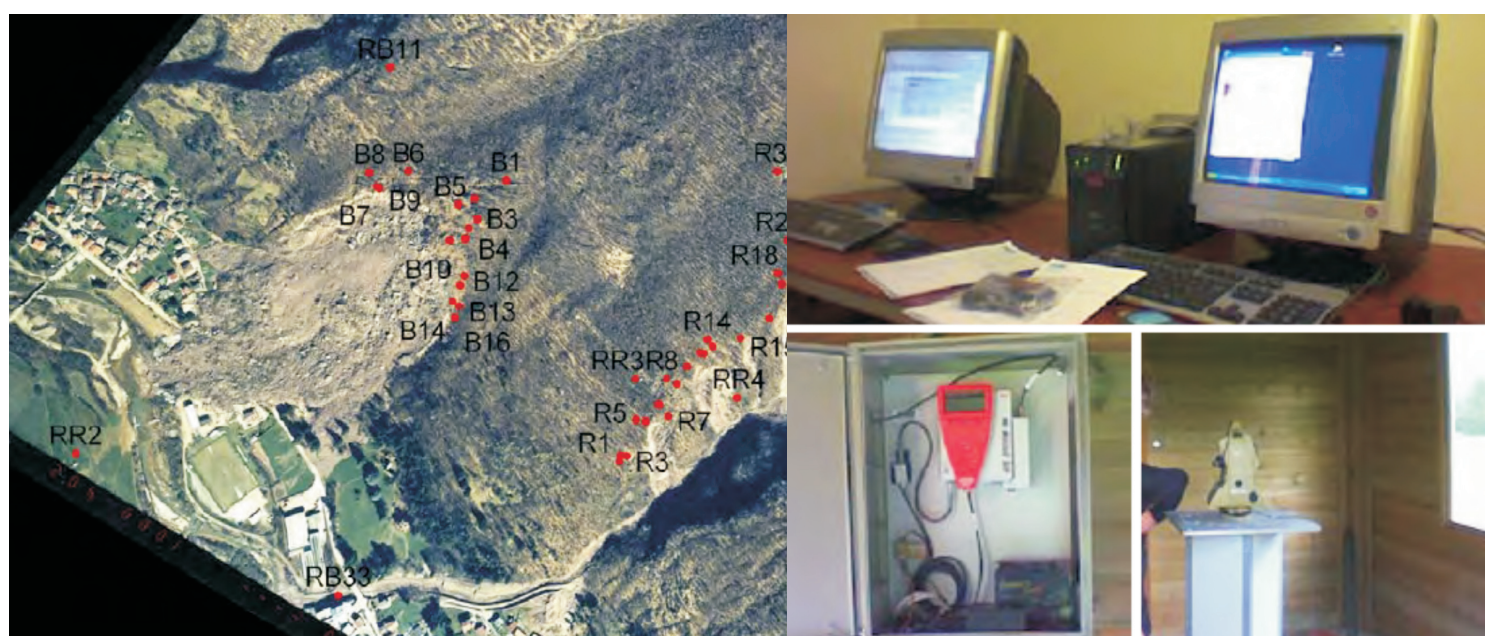

Fig. 5 - Sistema de Monitorização e Alerta de Movimentações em massa - Cortenova - Itália.

Fonte:Leica geosystems truestories, sem data.

D. Alerta: Esta operação será o culminar dos procedimentos para a intervenção rápida em caso de movimentação de massas. A plataforma será constituída por um conjunto de sistemas robóticos de estações totais com miras distribuídas pela área sensível a intervir. São introduzidas as coordenadas conhecidas, com precisão milimétrica, no sistema robótico para cada uma das miras. Os aparelhos robóticos, ao fazerem as leituras constantes das miras, calculam os vectores dos movimentos e as direcções, permitindo assim uma monitorização em tempo real e alerta em caso de haver uma grande diferença de leitura de coordenadas entre as coordenadas tidas como verdadeiras e as leituras obtidas num determinado instante.

O produto final será um modelo de actualização permanente de cartografia de risco de movimentação de massas, com aplicação de modelos de previsão de cenários, incluindo variáveis como: Hora do dia (consoante a hora do dia, assim poderá haver diferentes cenários de risco para a vida humana); Vectores de direcção e velocidade;
Cálculo de volumes; Carta de declives; Carta de uso dos Solos; Carta Geológica e outros.

Desta maneira, o planeamento e prevenção de riscos será sempre mais preciso e incidindo em zonas sensíveis, permitindo uma melhor compreensão da realidade local, auxiliando o trabalho de todos os agentes no terreno.

Abaixo apresentamos de forma simplificada um diagrama com a aplicação do módulo de movimentação de massas.

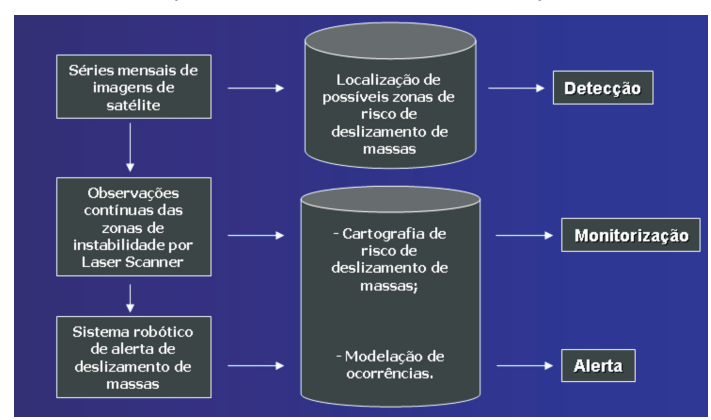

Fig.6 - Diagrama de aplicação do módulo de movimentação de massas.

Fonte: SRPC, IP-RAM. 
Módulo 2 - Sistema de alerta para Incêndios Florestais

Este módulo será constituído por uma plataforma que integra um sistema de prevenção com um sistema de alerta para incêndios florestais. A base de prevenção e previsão terá uma forte componente de modelação recorrendo a dados geográficos e meteorológicos consistentes e precisos de modo a dar maior garantia sobre os dados obtidos.

Será produzida uma Carta de Previsão de Incêndios Florestais que, cruzando várias variáveis meteorológicas em tempo real - temperatura, vento, humidade e precipitação - permitem verificar o risco de incêndio em cada uma das situações meteorológicas, garantindo assim a previsão de risco de incêndio florestal e métodos geoestatísticos. Os inputs necessários para determinar esta carta são os seguintes:

- Carta de Ocupação de solos: já existe uma carta para a RAM, referente ao ano 2007, que classifica o uso do solo até um $5^{\circ}$ nível, permitindo uma rigorosa e precisa atribuição do grau de perigosidade. Esta carta está de acordo com os três níveis de classificação europeia CORINE Land Cover permitindo uma integração com a restante informação europeia;

- Inventário de Incêndios Florestais: esta informação será fundamental para conhecer as áreas de maior incidência de incêndios, atribuindo um maior grau de probabilidade de incêndio para estas zonas;

- Cartas meteorológicas: cartas com variáveis meteorológicas de modo a caracterizar o clima e as zonas da região;

- Modelo digital do Terreno (DEM): permite-nos saber, localmente, declives, exposições, altitudes, visibilidades, entre outras informações de interesse.

- Dados meteorológicos em tempo real: serão as únicas variáveis, dado que os restantes inputs são "estáticos". Com esta informação em tempo real, conseguimos estimar o índice de risco de incêndio local para cada uma das estações meteorológicas e modelar, com recurso a modelos matemáticos, para o restante território.

Assim, na mesma plataforma tecnológica, haverá integração de cartografia temática e de base, de dados meteorológicos em tempo real, do mapa da estimativa de risco de incêndio, de mecanismos de modelação espacial da previsão de propagação, localização de estradas, caminhos florestais e áreas sensíveis (casas, escolas, etc), e câmaras infravermelhas.

As câmaras infravermelhas fazem parte de uma nova filosofia utilizada no combate aos fogos florestais, que passa pela intervenção rápida durante a fase inicial dos mesmos, implicando a utilização de menos recursos humanos e materiais. Este sistema permite uma identificação positiva e precisa não só da posição (coordenadas) do incêndio, mas também produz imagens do mesmo e recolhe dados atmosféricos, fornecendo assim valiosos pontos de referência para as equipas no terreno e também informações das condições climatéricas para uma correcta adaptação das técnicas de combate ao incêndio florestal.

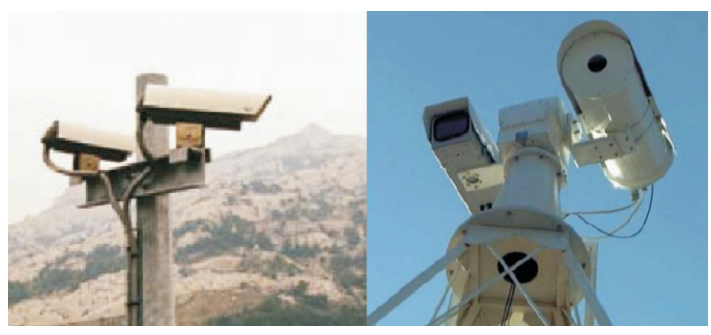

Fig. 7 - Câmaras com sistemas de detecção automática de incêndios florestais

Fonte: Incêndios florestais, sem data.

O cruzamento e integração desta informação irá permitir atingir os seguintes objectivos:

1) Alerta;

2) Previsão;

3) Planeamento;

4) Intervenção rápida;

5) Gestão de Meios;

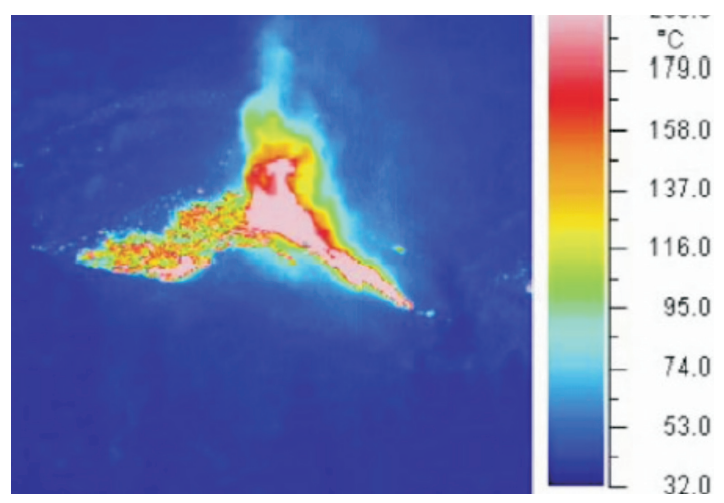

Fig. 8 - Imagem infra-vermelho de fogo florestal Fonte: Incêndios florestais, sem data.

\section{Módulo 3 - Sistema de alerta de cheias}

Este módulo será criado para projectar alertas de cheias rápidas através do sistema de sensores de leituras de caudais em combinação com estações pluviométricas. Esta plataforma terá acesso a sensores de medição do caudal, disparando o alerta quando este excede um determinado valor predefinido. Por outro lado, permite ainda uma monitorização do cenário através da previsão com recurso às estações meteorológicas colocadas em locais estratégicos. Assim, o sistema verifica se a precipitação local antevê o aumento do caudal de forma a provocar o aumento do caudal da ribeira. 


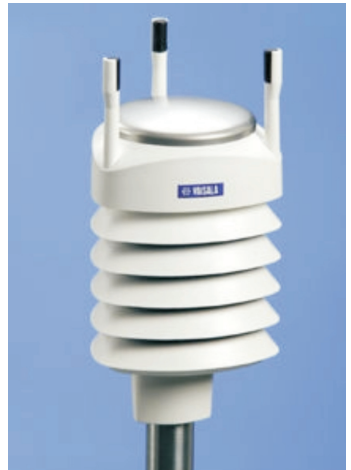

Fig. 9 - Estação meteorológica Fonte: www.directindustry.es

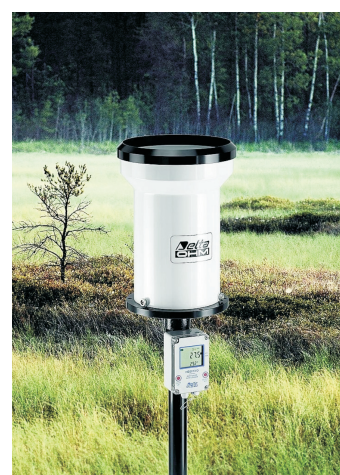

Fig. 10 - Pluviómetro Fonte: www.directindustry.es
Este módulo será representado por cartas de base hidrográfica onde serão projectados cenários, em vários locais sensíveis e em várias horas do dia, e a definição da intervenção em caso de alerta. Haverá ainda a componente de modelação do terreno com grande precisão, permitindo estudar escoamentos máximos através da colocação de sensores de cheias nas principais ribeiras.

De modo a obter cartografia com maior rigor, serão necessários os seguintes inputs:

- Registo histórico de ocorrências e cheias, inundações e galgamentos costeiros;

- Rede hidrográfica (hierarquia e magnitude);

- Carta de declives;

- Litologia (permeabilidade);

- Carta de Ocupação de solos;

- Área de bacia de drenagem;

- Topografia dos fundos de vales e de depressões;

- Localização de pontos e áreas sensíveis, com grandes aglomerados populacionais (hotéis, hospitais, escolas, etc);

- Nível médio das águas do mar;

- Nível da maré astronómica;

- Sobre-elevação meteorológica;

- Agitação marítima - dados de observação e de modelos;

- Batimetria;

- Topografia;

- Geometria da linha de costa;

Estes dados serão cruzados com os dos sensores, medidores dos dados do nível das ribeiras e de índice de pluviosidade, localizados em pontos estratégicos, para obtenção de informação meteorológica necessária para a monitorização das principais ribeiras e sistema de alerta, quando o caudal atingir um determinado nível. Esta informação será sempre transmitida em tempo real para o Centro Integrado de Comunicações/CROS, de modo a permitir o acompanhamento e gestão de situações de emergência.

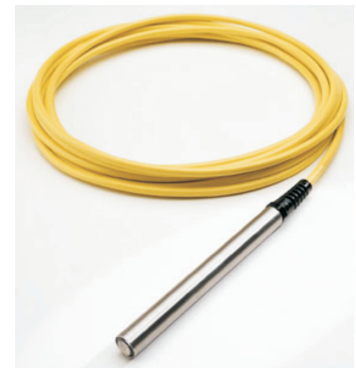

Fig. 11 - Leitor de sensor de nível de caudal

Fonte: www.globalw.com

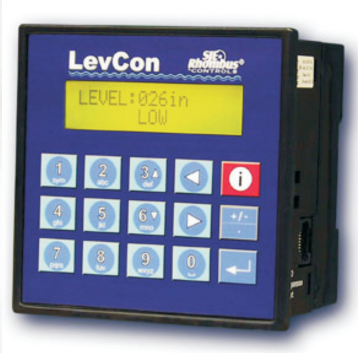

Fig. 12 - Ssensores de leitura de nível de caudal (altura) Fonte: www.globalw.com
Aquisição de Cartografia Temática e Análise de Zonas de Riscos Naturais

A produção de cartas temáticas deverá ser efectuada de acordo com as especificações técnicas do "Guia Metodológico para a produção de Cartografia Municipal de risco e para a criação de sistemas de informação geográfica de base municipal”, segundo Despacho n. ${ }^{\circ}$ 27660/2008, de 29 de Outubro de 2008, dos Secretários de Estado da Protecção Civil e do Ordenamento do Território e das Cidades. Saliente-se, no entanto, que o referido Guia sofrerá as necessárias adaptações para a sua aplicação na Região Autónoma da Madeira.

Para a elaboração das referidas cartas, será ainda tomada em consideração a Directiva INSPIRE (Directiva 2007/2/EC do Parlamento Europeu e do Conselho, de 14 de Março de 2007) que entrou em vigor a 15 de Maio de 2007 e tem por objectivo estabelecer um quadro legal para a criação da Infra-estrutura Europeia de Informação Geográfica.

Consoante o tipo de risco, serão utilizadas técnicas de detecção e análise de riscos e susceptibilidades bem como a determinação dos locais onde se procederá à colocação de sensores de avaliação de risco.

Equipar o Comando Regional de Operações de Socorro e Viaturas com sistemas de comunicação, hardware e transmissão de dados

A última fase do projecto refere-se à integração da informação procedente dos sistemas de alerta. 0 objectivo é facilitar aos técnicos o rápido acesso aos dados e à definição dos cenários para uma intervenção eficaz como pilar fundamental, conjugada com medidas de prevenção adequadas. Neste âmbito, é necessário dotar o Comando Regional de Operações de Socorro com uma estrutura de controlo funcional, totalmente operacional em caso de catástrofes naturais, e que 
consiga integrar as informações provenientes dos vários sistemas de alerta e ainda a comunicação bilateral entre Viaturas/Centro Integrado de Comunicações/ CROS. Face à necessidade de ter o sistema sempre funcional, a informação estará disponível em dois servidores, localizados em áreas diferentes.

A existência de três áreas distintas no CROS vai permitir uma intervenção rápida dos meios de socorro e emergência:

- Um posto de trabalho na área de gestão de conteúdos e planeamento, com o objectivo de planeamento, gestão, análise e relatórios. Funciona como área de administração do sistema com acesso total às bases de dados, vocacionado para a divisão de planeamento e prevenção de emergência. Permite ainda actualização de toda a base cartográfica, de modo a manter a informação o mais actual possível (Gabinete de Apoio Técnico).

- Dois postos de trabalhos de coordenação e intervenção, que monitorizam os dados e alertas e coordenam os meios. O grande objectivo destes postos será a rápida e eficaz comunicação entre os vários intervenientes, visualização dos vários cenários para uma rápida tomada de decisão e eficaz gestão de meios no terreno (Célula de Planeamento, Operações e Informações/CROS, Célula de Logística, Meios especiais e Comunicações/CROS) e Centro Integrado de Comunicações/(CROS)).

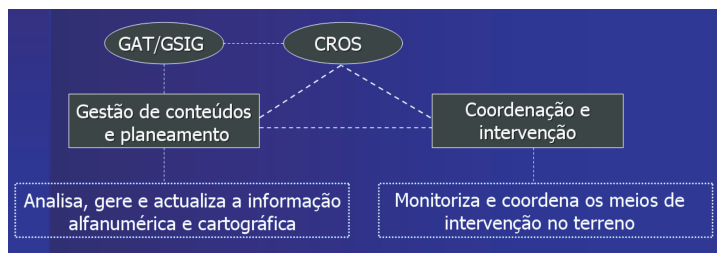

Fig.13 - Diagrama de aplicação da integração da informação procedente dos sistemas de alerta. Fonte: SRPC, IP-RAM.

\section{Conclusão}

O objectivo é a criação de uma plataforma de detecção de ocorrências, accionamento de mecanismos e intervenção rápida, assim como o seu planeamento e acompanhamento, possibilitado a centralização de informação e gestão na central de controlo. Deste modo, pretende-se ter uma caracterização mais real e mais exaustiva dos cenários de modo a poder tomar as decisões correctas em menor tempo possível.
Pode-se dividir o projecto em 4 grandes intervenções:

Prevenção: Pretende-se instituir mecanismos de prevenção e antecipação de ocorrência. Com base na produção de cartografia de zonas de susceptibilidade, perigosidade, vulnerabilidade e riscos dos vários tipos de ocorrências, é essencial a criação de informação útil para auxílio ao planeamento de emergência e, consequentemente, ao Ordenamento do Território da Região.

Planeamento: Com recurso às novas TIC associadas às ciências geográficas, pretende-se criar cenários relacionados com os vários tipos de riscos naturais (movimentação de massas, incêndios e inundações) geradores de intervenções rápidas. Com estas operações, ambiciona-se implementar uma nova lógica de eficácia de serviços, recorrendo a ferramentas que descrevam e implementem operações pré-planeadas.

Alerta: Os mecanismos de alerta e a sua representação sobre diversas cartografias de base e temática, permitem, não só, localizar em tempo real ocorrências, mas prever cenários. Assim, através da distribuição de sensores de alerta em locais estudados, analisados e detectados através das cartas de risco, obter-se-á uma rede de alerta, com capacidade de intervenção, dos meios no terreno, mais rápida e eficiente.

Gestão Operacional dos meios: 0 objectivo é de caracterizar ocorrências, de modo a diminuir o tempo de intervenção e melhorar o acompanhamento em tempo real.

\section{Referências Bibliográficas:}

\section{ANAIS XIII SIMPÓSIO BRASILEIRO DE SENSORIAMENTO} REMOTO, 2007

\section{LEICA GEOSYSTEMS TRUESTORIES, sem data}

Lourenço, Luciano (2007) - "Riscos Naturais, antrópicos e mistos”. Territorium, 14, p.1009-113.

Lourenço, Luciano (2003) - Risco meteorológico de incêndio florestal, Núcleo de Investigação Científica de Incêndios Florestais, Coimbra, $188 \mathrm{p}$.

Sites consultados:

www.directindustry.es

www.globalw.com 